\title{
Efeito de formas de manejo em algumas propriedades físicas e químicas de um Latossolo Vermelho em diferentes agroecossistemas
}

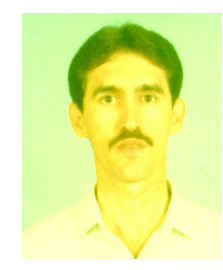

\author{
José F. Centurion ${ }^{1}$, Juliana P. Cardoso ${ }^{2} \&$ William Natale ${ }^{2}$ \\ 1 FCAV/UNESP. Via de Acesso Prof. Paulo Donato Castellane, CEP 14870-000, Jaboticabal, SP. E-mail: jfcentur@fcav.unesp.br (Foto) \\ ${ }^{2}$ FCAV/UNESP
}

Protocolo $120-25 / 09 / 2000$

\begin{abstract}
Resumo: Foram selecionadas, em 1998, quatro áreas de um Latossolo Vermelho Eutrófico típico muito argiloso, uma sob mata nativa (Floresta Latifoliada Tropical) e três sob cultivo de milho, cana-de-açúcar e pastagem, localizadas na Fazenda de Ensino e Pesquisa da Faculdade de Ciências Agrárias e Veterinárias, Campus de Jaboticabal. Caracterizaram-se as seguintes propriedades físicas: resistência do solo à penetração, realizada com penetrômetro de impacto, até $40 \mathrm{~cm}$ de profundidade e velocidade de infiltração de água, realizada com o duplo cilindro concêntrico, nos quatro sistemas de uso do solo. Foram realizadas determinações analíticas de fósforo, matéria orgânica, pH, cálcio, magnésio, potássio, hidrogênio + alumínio e calculados a soma de bases, CTC e saturação por bases. Todas as formas de uso e manejo empregadas provocaram degradação das propriedades físicas do solo em relação ao solo natural (mata), quantificada através de maiores valores de resistência do solo à penetração e menores valores de velocidade de infiltração de água. A degradação das propriedades químicas dos solos nos agroecossistemas estudados foi maior nas culturas de cana-de-açúcar e milho, que na pastagem. A degradação das propriedades físicas causou ao solo níveis críticos mais limitantes ao desenvolvimento das culturas, que aqueles referentes às propriedades químicas.
\end{abstract}

Palavras-chave: sistemas de uso do solo, latossolo, atributos físicos e químicos

\section{Physical and chemical properties of an oxisol in different agroecosystems}

\begin{abstract}
The experiment was carried out in 1998 on four agroecosystems on a very clayey Red Latosol eutrophic (Oxisol). One of them was covered with native vegetation (tropical rain forest) and the others were under corn, sugarcane and pasture cultivation. The experiment was located at FCAV - Research and Teaching Farm, Jaboticabal Campus, UNESP, São Paulo State, Brazil. In order to assess the effects of the agroecosystems, two soil physical properties were evaluated: soil penetration resistance (cone penetrometer) and infiltration rate (double ring infiltrometer). The following chemical properties were also studied: phosphorus, organic matter, $\mathrm{pH}$, calcium, magnesium, hydrogen + aluminum, sum of bases, CEC and base saturation. All agricultural agroecosystems caused degradation of soil physical properties as compared to the native soil. The deterioration was less intense under corn than sugarcane and more intense with pasture. Increase of soil penetration resistance and reduction of infiltration rate showed this degradation. The degradation of soil chemical properties was higher with sugarcane and corn than with pasture. The damages on soil physical properties caused by agricultural agroecosystems were more restrictive to crop development than the effects on soil chemical properties.
\end{abstract}

Key words: land use system, Oxisol, physical and chemical attributes

\section{INTRODUÇÃO}

A alteração de ecossistemas naturais ocorre na medida em que eles vão sendo substituídos por atividades voltadas para fins industriais ou produção de alimentos, provocando degradação, proveniente de uso e manejo inadequado dos solos. Dentre os vários sistemas de uso existentes, as maiores alterações ocorrem na agricultura tradicional, com capital e nível tecnológico mínimos, e no sistema agroquímico, com alto investimento de capital. Segundo Weid (1996), em relação à eficiência agronômica, o sistema agroquímico superou todos que o antecederam, embora os resultados não tenham sido homogêneos, comparando-se os distintos ecossistemas em que foi implantado. Como esse sistema depende intrinsecamente do uso de recursos não-renováveis (combustível, fertilizantes etc.), a questão da sustentabilidade está diretamente vinculada à durabilidade previsível desses recursos. Por outro lado, a agricultura tradicional requer baixo nível de consumo de 
insumos externos à propriedade e, conseqüentemente, depende pouco do aporte de energia externa, buscando-se adaptar o máximo possível ao meio ambiente, de forma que, quanto mais heterogêneo for o meio, mais diversificado será o sistema, no tempo e no espaço.

A retirada da cobertura vegetal original e a implantação de culturas, aliadas a práticas de manejo inadequadas, promovem o rompimento do equilíbrio entre o solo e o meio, modificando suas propriedades químicas, físicas e biológicas, limitando sua utilização agrícola e tornando-o mais suscetível à erosão.

Silva \& Ribeiro (1997) comentando sobre o manejo físico de solos sob pastagem, relatam que há ampla evidência experimental da limitação do potencial produtivo das culturas por inadequadas condições físicas do solo. Neste contexto, os solos cultivados com pastagens carecem desse tipo de avaliação.

O município de Jaboticabal está localizado na região de Ribeirão Preto, Estado de São Paulo, apresentando nível elevado em relação à aplicação de tecnologias no setor agropecuário, predominando a cultura da cana-de-açúcar, sendo que culturas anuais e pastagens ocorrem com menor freqüência, implicando no uso intensivo de mecanização. $\mathrm{O}$ aumento de mecanização na agricultura envolve o uso de máquinas pesadas, as quais, em condições desfavoráveis de umidade do solo, podem provocar degradação através da compactação e redução de infilltração de água em relação ao solo sob condição natural.

O objetivo deste trabalho foi avaliar as alterações das propriedades físicas e químicas de um Latossolo Vermelho, sob diferentes formas de manejo, ou seja, cultivado com pastagem, milho e cana-de-açúcar. As variações encontradas são analisadas em relação ao solo em seu estado natural (mata).

\section{MATERIAL E MÉTODOS}

\section{Características do meio físico}

O município de Jaboticabal acha-se localizado na parte nordeste do Estado de São Paulo, na província geomorfológica denominada Planalto Ocidental, transicional com as "cuestas" basálticas, de acordo com o Instituto de Pesquisas Tecnológicas (1981). Sua situação geográfica é definida pela latitude Sul $21^{\circ} 04^{\prime}$ a $21^{\circ} 21^{\prime}$ e longitude Oeste de Greenwich $48^{\circ} 08^{\prime}$ a $48^{\circ} 26^{\prime}$, conforme consta nas cartas planialtimétricas da Coleção Carta do Brasil, editada segundo Brasil (1971). A altitude varia de 480 a $630 \mathrm{~m}$, o clima é do tipo Cwa, isto é, mesotérmico de inverno seco (Brasil, 1960) e a vegetação primária é do tipo floresta latifoliada tropical, segundo Romariz (1968). Atualmente, a área de estudo, que corresponde a 817,8 ha, encontra-se ocupada pelos campos experimentais da Faculdade de Ciências Agrárias e Veterinárias, Campus de Jaboticabal, cujo relevo varia de plano a ondulado, com predominância de declives até $8 \%$; o material geológico é formado pelos arenitos do Grupo Bauru, formação Adamantina, Grupo São Bento, formação Serra Geral (Instituto de Pesquisas Tecnológicas, 1981) e por rochas alcalinas (Barcha et al., 1984).

O solo da área em estudo foi classificado por Andrioli \& Centurion (1999) como Latossolo Vermelho Eutrófico típico, textura muito argilosa a moderado caulinítico oxídico mesoférrico relevo suave ondulado (LVe).

\section{Agroecossistemas estudados}

As áreas estudadas apresentaram as seguintes características:

1) Floresta Latifoliada Tropical: corresponde à área preservada de mata nativa, utilizada como referencial para avaliação das alterações das propriedades físicas e químicas do solo, resultantes de diferentes modalidades de usos agrícolas, considerados agroecossistemas.

2) Cultura do milho: esta área foi utilizada em rotação (ano a ano) com a cultura da soja, por 10 anos. O preparo do solo foi feito com grade aradora e no plantio foram colocados $300 \mathrm{~kg} \mathrm{ha}^{-1}$ de fertilizante com a fórmula 4-20-20 e $200 \mathrm{~kg} \mathrm{ha}^{-1}$ da fórmula 20-0-20 em cobertura, seguindo-se a recomendação para culturas no estado de São Paulo (Raij et al., 1996).

3) Cultura da cana-de-açúcar: é cultivada na área há mais de 30 anos, seguindo preparo com arado de aiveca e uma gradagem com grade pesada; no momento da amostragem, a cultura estava no segundo ano de corte.

4) Pastagem cultivada: a espécie semeada é a Panicum maximum (Colonião). O plantio ocorreu em 1978 e a área não recebe fertilizantes nem corretivos desde 1990. O sistema de pastejo era contínuo, utilizado por bovinos com 1,5 a 2 unidades animal (animal de $450 \mathrm{~kg}$ de peso vivo).

\section{Determinações físicas e químicas}

Em 1998, foram selecionadas quatro áreas adjacentes, uma sob mata nativa (Floresta Latifoliada Tropical) e as outras sob cultivo de milho, cana-de-açúcar e pastagem. Amostraram-se, aleatoriamente, sete pontos em cada área. Em cada ponto foi determinada a resistência do solo à penetração, com penetrômetro de impacto, em intervalo de 5 até $40 \mathrm{~cm}$ de profundidade de acordo com Stolf(1991). A determinação foi realizada logo após um período de chuvas, quando a umidade do solo estava próxima à capacidade de campo; determinou-se, também, a velocidade de infiltração de água, com o duplo cilindro concêntrico de carga variável, seguindo-se recomendação de Bernardo (1980) nos quatro sistemas de uso do solo.

Retiraram-se sete amostras compostas por três pontos, nas profundidades de $0-20$ e $20-40 \mathrm{~cm}$, para fins de análise da fertilidade do solo, nos quatro sistemas de uso do solo, para as determinações analíticas de fósforo, matéria orgânica, $\mathrm{pH}$ em $\mathrm{CaCl}_{2}$, cálcio, magnésio e hidrogênio + alumínio, sendo calculadas soma de bases, CTC e saturação por bases (V\%). As análises foram realizadas de acordo com Camargo et al. (1986).

\section{Análises estatísticas}

Os efeitos dos sistemas de uso do solo sobre as propriedades químicas em cada profundidade, foram verificados a partir da análise de variância, seguindo-se um delineamento inteiramente casualizado, com sete repetições. A diferença entre as médias foi avaliada pelo teste de Tukey a 5\%.

\section{RESULTADOS E DISCUSSÃO}

\section{Alterações provocadas pelo manejo dos solos}

Objetivou-se fazer uma análise comparativa entre as possíveis alterações nas propriedades do solo sob cultivo, em relação ao solo em seu estado natural (mata). 


\section{Propriedades físicas do solo}

A Figura 1 ilustra o que ocorreu com a resistência do solo à penetração do penetrômetro, no solo natural, sob pastagem, milho e cana-de-açúcar. Em todos os sistemas de manejo do solo houve tendência de formação de camada compactada em diferentes profundidades do solo, medidas pelo penetrômetro. A intensidade desta camada é variável com a profundidade de atuação dos diversos implementos utilizados no preparo do solo, no qual, quando sob pastagem, ocorreu a maior compactação, situação em que os animais, através do pisoteio, foram os responsáveis pelo adensamento, que se encontra, de forma marcante, na camada mais superficial, refletindo as condições físicas do solo, como relata Cabeda (1984).

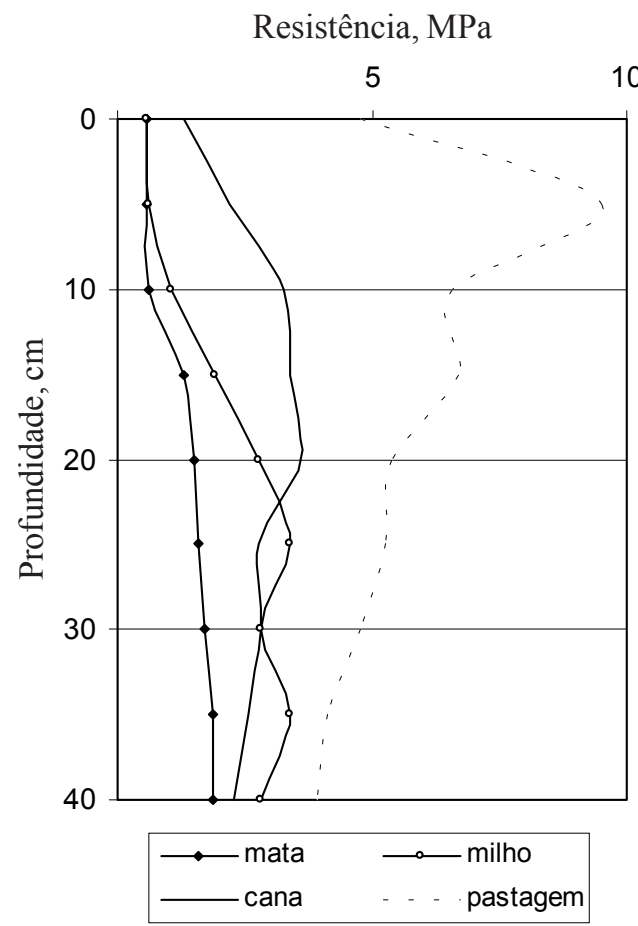

Figura 1. Resistência do solo á penetração para solo sob mata, milho, cana-de-açúcar e pastagem

A formação de camada compactada a diferentes profundidades, com uso e manejo de solo, é quantificada pelos valores maiores que 2,0 MPa, limite crítico sugerido por Tormena (1998) em Latossolo Roxo, para influenciar o desenvolvimento das culturas; todavia, Rosolem et al. (1999) concluíram que resistência do solo à penetração da ordem de 1,3 MPa reduz pela metade o crescimento das raízes seminais adventícias do milho.

Segundo Imhoff et al. (1999) valores de resistência mecânica do solo entre 2 e $3 \mathrm{MPa}$, são considerados limitantes ao desenvolvimento radicular; assim, todos os sistemas de manejo induziram à formação de camadas compactadas, em níveis que afetam o desenvolvimento radicular das culturas.

A infiltração de água indica diferenças no comportamento hidrodinâmico do solo, em função da alteração de sua estrutura. Na Figura 2 estão ilustrados os valores de velocidade de infiltração de água, obtidos para o solo natural (mata) e demais sistemas de manejo estudados. Considerando-se que a infiltração de água reflete as condições físicas do solo, como estrutura, porosidade e ausência de camadas compactadas (Baumer \& Bakermans, 1973) deduz-se que nos solos estudados elas sofreram modificações acentuadas, em função do manejo. As maiores alterações foram encontradas no solo sob pastagem, em função da elevada resistência do solo à penetração de água, devido à compactação formada na camada superficial. Os baixos índices de infiltração, como relatam Bragagnolo \& Mielniczuk (1990) apresentam, como conseqüência, escoamento superficial e erosão. Para o presente trabalho, a perda de solo ocorrerá provavelmente, no período de excedente hídrico, especialmente nos meses de dezembro, janeiro e fevereiro.

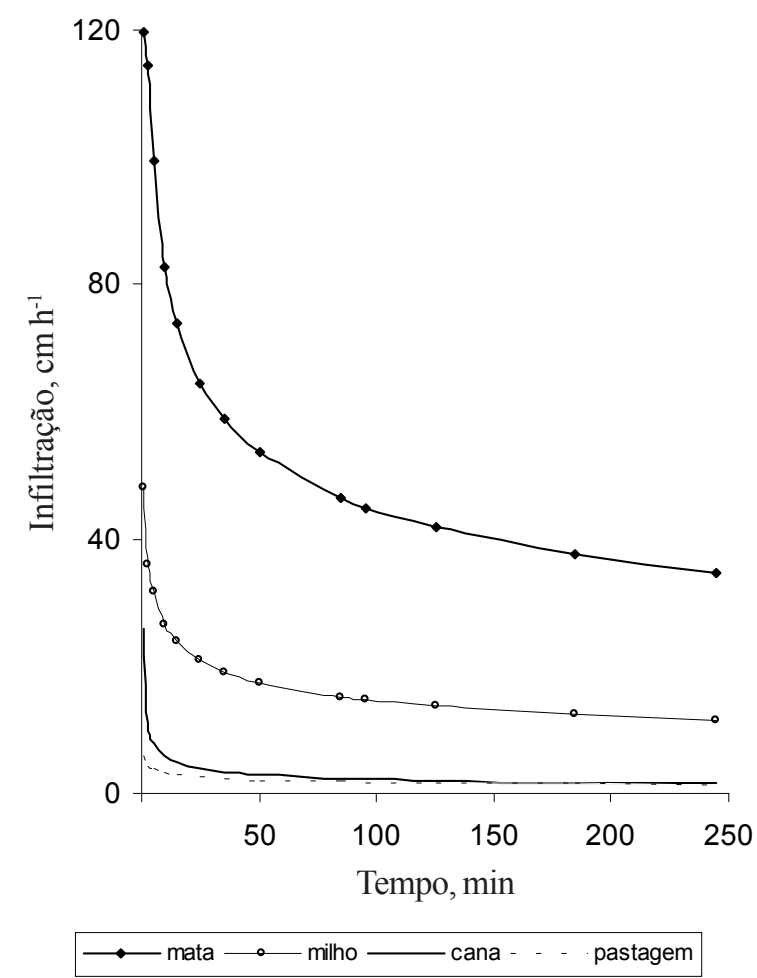

Figura 2. Infiltração de água no latossolo sob mata, milho, cana-de-açúcar e pastagem

\section{Propriedades químicas do solo}

Na Tabela 1 tem-se os valores médios das análises químicas para fins de fertilidade do solo dos sistemas (solo sob mata, milho, cana-de-açúcar e pastagem) obtidos para o solo estudado, em duas profundidades.

Todos os nutrientes analisados no solo sob mata, possuem níveis mais altos, apresentando diferenças estatísticas em relação aos demais tratamentos, cujos dados evidenciam que o manejo do solo, independente da cultura utilizada, provocou decréscimo nos níveis dos macronutrientes e aumento da acidez do solo, o que indica degradação das propriedades químicas do solo, em relação ao solo natural.

Verifica-se, através da Tabela 1 , decréscimo dos teores de matéria orgânica do solo, tanto na profundidade de 0 - 20 como de 20 - $40 \mathrm{~cm}$, quando se comparam a mata e os diferentes sistemas de exploração. Rando (1981) informa que, devido ao revolvimento dos solos sob cultivo, a aeração é maior, sendo a mineralização de matéria orgânica favorecida, o que explica os resultados observados.

Moraes (1993) cita que, dentre as alterações químicas no solo, promovidas pela pastagem, tem-se o evidente aumento da CTC por efeito da elevação do teor de matéria orgânica, 
Tabela 1. Valores médios ${ }^{1}$ das análises químicas para fins de fertilidade do solo, nos diversos tipos de manejo estudados

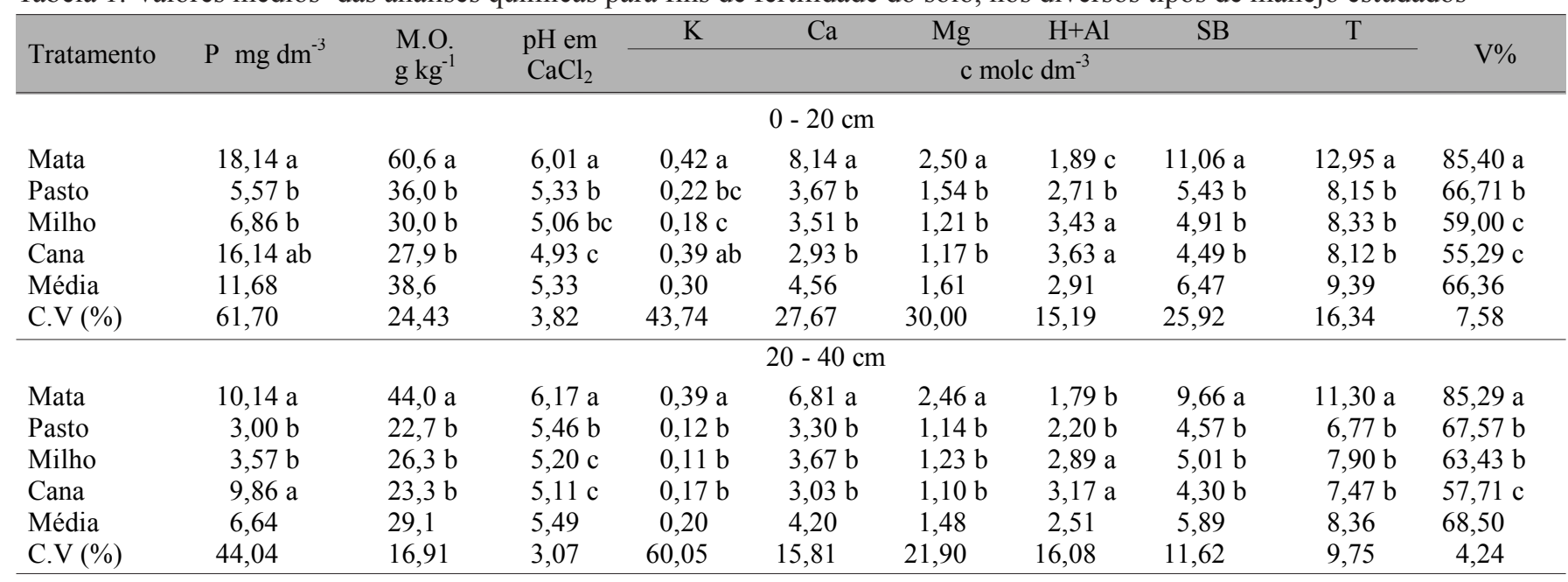

") Médias seguidas pela mesma letra, na coluna, não diferem estatisticamente, pelo teste de Tukey, a $5 \%$ de probabilidade

quando comparada com outras culturas, pois esta apresenta alta densidade de cargas, de natureza $\mathrm{pH}$ dependente, enquanto na argila a densidade de cargas é mais baixa; porém, no presente trabalho o solo sob milho, cana-de-açúcar e pastagem, apresenta menores teores de matéria orgânica e redução da CTC, quando comparado ao solo sob mata.

No presente trabalho, o solo sob pastagem apresentou menor teor de $\mathrm{P}$ que o solo sob milho e cana-de-açúcar, devido a área sob pastagem não ter recebido fertilizantes nem corretivos, nos últimos 10 anos. Segundo Bayer (1992) sistemas que apresentam reduzido revolvimento do solo, a exemplo da pastagem, acarretam maior concentração de $\mathrm{P}$ disponível na camada superficial e uma estratificação, com redução acentuada, a medida em que aumenta a profundidade.

$\mathrm{O}$ acúmulo de $\mathrm{P}$ na superfície do solo é decorrente da decomposição dos resíduos de plantas e dejetos animais, diminuição da fixação em função do seu menor contato com os constituintes inorgânicos do solo e de aplicações anuais de fertilizantes fosfatados, de acordo com Moraes (1993).

Dentre as gramíneas cultivadas, as pastagens são as menos exigentes em fertilidade (Carvalho Filho, 1999) e as que melhor protegem o solo contra a erosão; assim, percebe-se que nas áreas cultivadas até a profundidade de $20 \mathrm{~cm}$, as culturas do milho e da cana-de-açúcar exportam mais bases que as pastagens.

Embora tenha ocorrido redução no conteúdo da soma de bases em função do manejo do solo, os valores de saturação por bases estão próximos dos níveis exigidos pelas culturas estudadas. De acordo com Raij et al. (1996) a aplicação de calcário para as culturas do milho, cana-de-açúcar e pastagem, deve ser feita para elevar a saturação por base (V) a 70,60 e $60 \%$ respectivamente. A manutenção de valores elevados de saturação por base nos diferentes agroecossistemas estudados, está relacionada à alta fertilidade natural deste solo, ou seja, $\mathrm{V}$ de cerca de $85 \%$ (eutrófico). Ressalta-se que os Latossolos predominantes no Brasil apresentam, geralmente, $\mathrm{V}<50 \%$, ou seja, são distróficos.

\section{CONCLUSÕES}

1. Todas as formas de uso e manejo empregadas induziram, em ordem crescente, milho, cana-de-açúcar e pastagem, à degradação das propriedades físicas do solo em relação ao solo natural (mata). Esta degradação foi quantificada através de maiores valores de resistência do solo à penetração e menores valores de velocidade de infiltração de água.

2. O cultivo de milho e cana-de-açúcar afetou mais intensamente as propriedades químicas do Latossolo Vermelho Eutrófico que a pastagem

3. Independente das formas de manejo, as propriedades físicas foram mais afetadas que as propriedades químicas do solo.

\section{LITERATURA CITADA}

Andrioli, I.; Centurion, J.F. Levantamento detalhado dos solos da Faculdade de Ciências Agrárias e Veterinárias de Jaboticabal. Congresso Brasileiro de Ciência do Solo, 27,1999. Brasília. Anais... Brasília: Sociedade Brasileira de Ciência do Solo, 1999. (CD-Rom).

Barcha, S.F.; Ellert, N.; Valarelli, J.V.; Boni, N.R. Intrusão alcalina de Jaboticabal, SP. Geociências, São Paulo, v.3, p.21-38, 1984.

Baumer, K.; Bakermans, W.A.P. Zero tillage. Advances in Agronomy, New York, v.25, p.77-125, 1973.

Bayer, C. Características químicas do solo, nutrição e rendimento do milho afetados por métodos de preparo e sistemas de culturas. Porto Alegre, 1992.185p. Dissertação Mestrado

Bernardo, S. Água no solo. Viçosa: Universidade Federal de Viçosa. 1980.28p. Boletim de Extensão

Bragagnolo, N.; Mielniczuk, J. Cobertura do solo por palha de trigo e seu relacionamento com a temperatura e umidade do solo. Revista Brasileira de Ciência do Solo, Campinas, v.14, p.369-374, 1990.

Brasil. Ministério da Agricultura, Serviço Nacional de Pesquisas Agronômicas. Comissão de Solos: Levantamento de reconhecimento dos solos do Estado de São Paulo: contribuição à carta de solos do Brasil. Boletim Serviço Nacional de Pesquisa Agronômica, Rio de Janeiro, v.12, 1960.634p. 
Brasil. Ministério do Planejamento. Fundação Instituto Brasileiro de Geografia. Departamento de Cartografia. Folha SF-22-XD-III-3, Jaboticabal, Folha SF-22-X-D-III-4, Guariba, Carta do Brasil. Rio de Janeiro, 1971. Esc. 1:50.000

Cabeda, M.S.V. Degradação física e erosão do solo. In: Simpósio de Manejo do Solo e Plantio Direto no Sul Brasil, 1, Simpósio de Conservação do Solo do Planalto, 3, 1984. Anais... Passo Fundo: PIUCS, UPF, 1984.

Camargo, O.A.; Moniz, A.C.; Jorge, J.A.; Valadares, J.M.A.S. Métodos de análise química, mineralógica e física de solos do Instituto Agronômico do Estado de São Paulo. Campinas: Instituto Agronômico, 1986. 94p. Boletim Técnico, 106

Carvalho Filho, A. Levantamento detalhado e alterações de alguns atributos provocados pelo uso e manejo dos solos da Faculdade de Agronomia de Ituverava, SP. Jaboticabal, 1999. 88p. Dissertação Mestrado

Imhoff, S.; Silva, A.P. da; Tormena, C.A. Curva de resistência: aplicações no controle da qualidade física de um solo sob pastagem. In: Congresso Brasileiro de Ciência do Solo, 27, 1999, Brasília. Resumos... (CD-Rom.)

Instituto de Pesquisas Tecnológicas. Mapa geomorfológico do Estado de São Paulo. São Paulo: IPT, 1981. Mapa, escala 1:1000.000

Moraes, A. de. Pastagem como fator de recuperação de áreas degradadas. In. Simpósio sobre Ecossistema de Pastagem, 2, 1993, Jaboticabal. Anais... p.191-215, 1993.

Rando, E.M. Alterações nas características e propriedades físicas de um Latossolo Roxo distrófico, ocasionadas pelo cultivo convencional. Lavras: Escola Superior de Agricultura de Lavras. 1981. 161p. Dissertação Mestrado
Romariz, D.A. A vegetação. In: Azevedo, A. (ed.) Brasil: A terra e o homem.; 2 Ed., 1968. v.1, p.521-572.

Rosolem, C.A.; Fernandez, E.M.; Andreotti, M.; Crusciol, C.A.C. Crescimento radicular de plântulas de milho afetado pela resistência do solo à penetração. Pesquisa Agropecuária Brasileira, Brasília, v.34, n.5, p.821-828, 1999.

Silva, A.J.N. da; Ribeiro, M.R. Caracterização de latossolo amarelo sob cultivo contínuo de cana-de-açúcar no estado de Alagoas: atributos morfológicos e físicos. Revista Brasileira de Ciência do Solo, Campinas, v.21, p.684-688, 1997.

Stolf, R. Teoria e teste experimental de fórmulas de transformação dos dados de penetrômetro de impacto em resistência do solo. Revista Brasileira de Ciência do Solo, Campinas, v.15, p.229-235, 1991.

Tormena, C.A. Caracterização e avaliação do intervalo hídrico ótimo de um Latossolo Roxo. Piracicaba: Escola Superior de Agricultura Luiz de Queiroz, Universidade de São Paulo. 1998. 106p. Tese Doutorado

van Raij, B.; Cantarella, H.; Quaggio, J.A.; Furlani, A.M.C. Recomendações de adubação e calagem para o Estado de São Paulo. 2. Ed. Campinas: Instituto Agronômico \& Fundação IAC, 1996. 285p. Boletim Técnico, 100.

Weid, J.M. von der. Conceitos de sustentabilidade e sua aplicação nos modelos de desenvolvimento agrícola. In: Alvarez, V.; Fontes, L.E.F.; Fontes, M.P.F. O solo nos grandes domínios morfoclimáticos do Brasil e o desenvolvimento sustentado. Viçosa: SBCS/UFV/DPS, 1996. p.353-366. 